\title{
A Comparison of Su and Lu Modeling of Hydro-Thermal Coupling Model Using Field Temperature Records
}

\author{
Jie Ren ${ }^{1 *}$, Wenbing Zhang², Bo Chen ${ }^{1}$, Lili Men¹, Chen Ma ${ }^{1}$, Lei Gan² \\ 'State Key Laboratory of Eco-hydraulics in Northwest Arid Region, Xi'an University of Technology, Xi'an, China \\ ${ }^{2}$ College of Water Conservancy and Hydropower Engineering, Hohai University, Nanjing, China
}

Received: 2 December 2019

Accepted: 21 May 2020

\begin{abstract}
The transport of materials and energy between rivers and riparian zones are driven by lateral hyporheic exchange and plays a vital role in regulating the ecological health of rivers. Owing to the limitations of models and methods, prior research has mainly focused on vertical hyporheic exchange in river systems. Combined with the collected riparian zone temperature and water level data, a 2D hydrothermal coupling model of the riparian zone was developed using the thermal conductivity model, and the fitting effects of the Lu et al. (2007) model and Su et al. (2016) model on temperature variations in riparian zone comparatively analyzed. Then, the dynamic variation characteristics of the riparian zone temperature and the lateral hyporheic exchange recharge pattern were investigated by the constructed models. The calibrated model could reasonably illustrate the variations in the riparian zone temperature, and the sensitivity analysis revealed that the hydraulic conductivity $\left(K_{s}\right)$ is the most sensitive factor to the temperature variations.
\end{abstract}

Keywords: riparian zone, thermal conductivity model, Lu et al. (2007) model, Su et al. (2016) model, sensitivity analysis

\section{Introduction}

The hyporheic zone (HZ), a water-saturated sediment layer within the riverbed and the riparian zone [1, 2], connects river bodies, sediments, and groundwater [3]. Between the overlying water and the groundwater, there are substances and energy whose exchange and transition constitute a vital part of the river ecosystem [4,5]. The hyporheic exchange is

*e-mail: renjie@xaut.edu.cn a vital physical process affecting the rivers' ecological health, which directly correlates with the biological and chemical reactions, including nutrient transport, oxygen supplementation, or carbon release of the surface water-groundwater systems in riverbeds and riparian zones. In addition, the hyporheic exchange plays a vital role in regulating the ecological health and physicochemical processes of rivers [6]. Consequently, the processes and characteristics of the hyporheic exchange are crucial for precise assessment and exploitation of water resources in the basin, as well as conservation and rehabilitation of healthy surface water and groundwater ecosystem. 
Currently, the research on the hyporheic exchange primarily focuses on the vertical exchange of riverbeds and surface water [7-10]; however, limited research exists on the river lateral hyporheic exchange [11-13], a process of water exchange between rivers and their riparian zone. Owing to the particularity of the interface between the surface water and the groundwater within the riparian zone, the location and the structure of the riparian zone differ from the riverbed in aspects such as a hyporheic exchange mechanism, ecological processes, and material migration; it is an essential embodiment of the complex edge effect in the riparian zone. Furthermore, owing to its crucial functionality in protecting rivers and groundwater, it has become a hot topic in many disciplines.

The studies mentioned above have primarily investigated river-related problems based on laboratory experiments or field temperature tracer tests. Of note, the corresponding costs are relatively high, and no effective hydro-thermal coupling model exists to analyze the water flow and thermal dynamics of the riparian zone. Thus, more attempts are warranted to find a suitable coupling model. As a key driving factor of the hydro-thermal coupling theory, soil thermal parameters (i.e., thermal conductivity, thermal diffusivity, and specific heat capacity) directly determine whether the model is sufficiently accurate. Some relevant studies have demonstrated that thermal conductivity is a vital factor that affects and determines the temperature field distribution of the soil during heat transfer [14, 15]. Steady-state methods broadly include heat flow meter method and guarded hot plate method [16, 17], which are normally used to measure medium and low thermal conductivity materials. Transient methods primarily include probe method, hot wire method, and plane source method [16]. The steady-state methods offer advantages of being stable and reliable, simple technical method, direct attainment of the absolute value of thermal conductivity, better repeatability, and higher accuracy in the process of measuring thermal conductivity. However, the steady-state methods take a long time to measure the thermal conductivity, causing the soil moisture to migrate because of temperature, which, in turn, affects the soil moisture content, resulting in a significant measurement error. Thus, in a strict sense, the steady-state methods are unsuitable for unsaturated soil. The transient methods are the primary method to measure the thermal parameters of soil, with characteristics such as rapid and straightforward measurement, extremely short measurement period, and small disturbance to soil. While the soil moisture content migrates because of temperature using the steady-state methods, only a small temperature rise occurs during the test measurement when using the transient methods. Thus, the moisture content in the soil sample could be regarded as unchanged.

However, owing to the cumbersome and timeconsuming measurement procedure of thermal conductivity, some scholars have proposed empirical model formulas for predicting thermal conductivity. In 1975, Johansen (1975) first introduced the concept of normalized thermal conductivity; he believed that the correlation between normalized thermal conductivity and saturation could simultaneously depict the impact of the soil type, porosity, moisture content, and mineral composition on the soil thermal conductivity. However, the proposed model could not consider the impact of the soil type on thermal conductivity and saturation. Based on the normalized thermal conductivity model [18], Côté and Konrad (2005) [19] established a correlation between thermal conductivity and saturation with the variable, where this factor depicts the impact of the soil type (grit, fine sand, silt, and clay) on the aforementioned relationship and the soil thermal conductivity. However, Côté and Konrad (2005) [19] did not quantify the boundary value of various soils. In addition, it was checked by $\mathrm{Lu}$ et al. (2007) [20] that the selection of value exerted a significant impact on the predicted soil thermal conductivity by implementing the Cote and Konrad model. Although Lu et al. (2007) [20] tested 12 types of soils, including sand, silt, and clay, they assumed that the quartz content of the soil would be equivalent to that of the sand. In addition, the thermal conductivity of solid particles and saturated soil samples was calculated, which lead to a higher value than the actual one. Moreover, the model for evaluating thermal conductivity of dry soil was developed based on the basis of the simple linear fitting method. The suggested model did not consider the impact of the soil property on the estimated results, thereby affecting the prediction accuracy of the final soil thermal conductivity. Su et al. (2016) [21] considered the impact of the organic matter content based on the $\mathrm{Lu}$ et al. (2007) [20] model. Comparing the improved model with the previous thermal conductivity model, $\mathrm{Su}$ et al. (2016) [21] found that the improved thermal conductivity model could better predict the soil thermal conductivity.

This major aims of this present study are to: (1) provide insights into the hydro-thermal functioning of riparian zones using a 2D numerical model applied to a well-documented field site in Nevada, US; (2) compare and analyze the simulation effects between the Lu et al. (2007) [20] model and Su et al. (2016) [21] model based on COMSOL Multiphysics [22] by numerical simulation and a field temperature records. Based on a better thermal conductivity model, this study investigates the dynamic variation characteristics of the riparian zone temperature and the lateral hyporheic exchange recharge pattern was investigated. In addition, the hydro-thermal model of the riparian zone contains many parameters. In this study, Morris global sensitivity analysis method was used to determine the primary factors pertinent to the temperature field of the riparian zone to decrease the workload of the model correction and provide an example for related studies. 


\section{Methodology}

\section{Field Investigations}

The water level and temperature data used in this study were obtained from a field test conducted by the U.S. Geological Survey, Nevada Water Science Center, Carson City, Nevada, within the Walker River Basin between March and November, 2012 [23]. U.S. Geological Survey researchers deployed water level and temperature sensors on the banks of the Fox irrigation channel for dynamical monitoring of water levels and temperatures. The polyvinyl chloride (PVC) temperature monitor rods with a filter screen was driven into the sedimentary layer in the riparian zone. Then, the authors hung temperature probes on the PVC rods 2.8 and $5.8 \mathrm{~m}$ away from the river center to measure the water temperature at depths of $0.50,0.70,1.50$ and $2.15 \mathrm{~m}$, and $1.20,1.70,2.30$ and $2.75 \mathrm{~m}$, respectively (Fig. 1). Using Schlumberger Micro-Diver pressure sensors and temperature data recorders, the water level and its temperature at the riverbed were monitored, respectively. The authors used the Type $\mathrm{Z}$ ibuttons inside bank piezometers and the Type L ibuttons for land surface soil temperature. During the test, the temperature and the water level data were controlled, recorded, and stored by the data recorder once per hour. Detailed descriptions of the study area and methods of data collection are provided elsewhere [13, 23].

\section{Model Description}

\section{Flow Model}

The saturated-unsaturated transient seepage field in the riparian zone can be displayed by the mixed form of
Richards equation [24]:

$\rho_{\mathrm{w}}\left(\frac{C_{\mathrm{m}}}{\rho_{\mathrm{w}} g}+S_{\mathrm{e}} S_{\mathrm{s}}\right) \frac{\partial p}{\partial t}+\nabla \rho_{\mathrm{w}}\left(-\frac{K_{\mathrm{s}} K_{\mathrm{r}}(\theta)}{\mu} \nabla\left(p+\rho_{\mathrm{w}} g z\right)\right)=Q_{\mathrm{m}}$

...where $\rho_{\mathrm{w}}$ is the density of water; $C_{\mathrm{m}}$ is the water capacity; $g$ is the acceleration of gravity; $S_{\mathrm{e}}$ is the relative saturation of soil; $S_{\mathrm{s}}$ is the elastic water storage rate; $p$ is the pressure; $t$ is the time; $\nabla$ is the Laplace operator; $\theta$ is the moisture content; $K_{\mathrm{s}}$ is the hydraulic conductivity of saturated media; $K_{\mathrm{r}}(\theta)$ is the relative hydraulic conductivity of the unsaturated zone and is the function of the moisture content $\theta ; \mu$ is the water dynamic viscosity; $z$ is the elevation of calculation point position, and $Q_{\mathrm{m}}$ is the water source.

Based on the van Genuchten formula [25], the soil hydraulic function is stated by:

$$
\begin{gathered}
\theta=\theta_{\mathrm{r}}+S_{\mathrm{e}}\left(\theta_{\mathrm{s}}-\theta_{\mathrm{r}}\right) \\
S_{\mathrm{e}}=\frac{1}{\left(1+\left(\alpha h_{\mathrm{p}}\right)^{\beta}\right)^{m}} \\
C_{\mathrm{m}}=\frac{\alpha m}{1-m}\left(\theta_{\mathrm{s}}-\theta_{\mathrm{r}}\right) S_{\mathrm{e}}^{\frac{1}{m}}\left(1-S_{\mathrm{e}}^{\frac{1}{m}}\right)^{m} \\
K_{\mathrm{r}}(\theta)=S_{\mathrm{e}}^{1 / 2}\left[1-\left(1-S_{\mathrm{e}}^{\frac{1}{m}}\right)^{m}\right]^{2}
\end{gathered}
$$

...where $S_{\mathrm{e}}$ is the relative saturation of soil; $\theta_{\mathrm{r}}$ is the residual moisture content; $\theta_{\mathrm{s}}$ is the saturated moisture

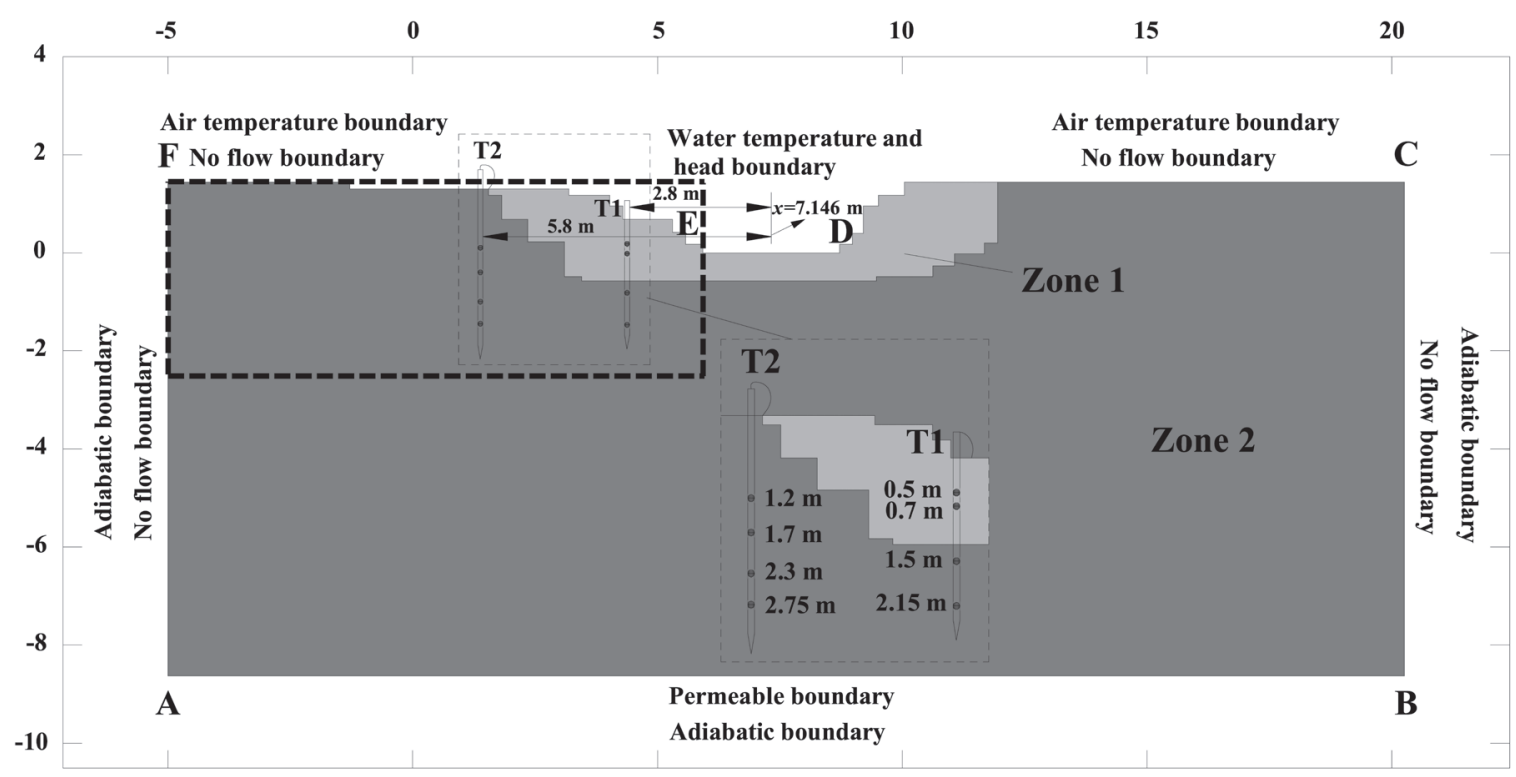

Fig. 1. The flow domain and the boundary conditions used in the COMSOL Multiphysics simulations (unit: m; modified from Ren et al. (2019)). 
content; $h_{\mathrm{p}}$ is the pressure head; $\alpha$ is the reciprocal of air entry value of soil moisture characteristic curve; $\beta$ is the parameter indicative of the gradient of the soil moisture characteristic curve and obtained by fitting the soil moisture characteristic curve; and $m=1-1 / \beta$.

\section{Heat Transport Model}

The saturated-unsaturated heat transfer model can be expressed by the following equation [26]:

$$
\begin{aligned}
\frac{\partial\left(\rho_{\mathrm{eq}} c_{\mathrm{eq}} T\right)}{\partial t}= & \nabla\left(\lambda_{\mathrm{eq}} \nabla T\right)+\nabla\left(\theta \rho_{\mathrm{w}} c_{\mathrm{w}} \mathbf{D}_{\mathbf{H}} \nabla T\right) \\
& -\nabla\left(\theta \rho_{\mathrm{w}} c_{\mathrm{w}} \mathbf{u} T\right)+Q_{\mathrm{s}}
\end{aligned}
$$

...where $\rho_{\text {eq }}$ is the equivalent density; $c_{\text {eq }}$ is the equivalent specific heat capacity; $T$ is the water temperature; $t$ is the time; $\nabla$ is a Laplace operator; $\lambda_{\text {eq }}$ is the equivalent thermal conductivity; $\theta$ is the moisture content which is equal to porosity in the saturated zone; $\rho_{\mathrm{w}}$ is the water density; $c_{w}$ is the specific heat capacity of water; $\mathbf{D}_{\mathbf{H}}$ is the hydrodynamic dispersion coefficient; $\mathbf{u}$ is the mean water velocity calculated by $\mathbf{u}=\mathbf{v} / \theta$ ( $\mathbf{v}$ is the Darcy seepage velocity); and $Q_{\mathrm{s}}$ is the heat source.

$$
\mathbf{D}_{\mathrm{H}_{i j}}=\alpha_{\mathrm{T}}|v| \delta_{i j}+\left(\alpha_{\mathrm{L}}-\alpha_{\mathrm{T}}\right) \mathbf{v}_{i} \mathbf{v}_{j}|v|
$$

...where $\alpha_{\mathrm{T}}$ is the transverse dispersion; $|v|$ is the vector magnitude of flow velocity; $\delta_{i j}$ is Kriging constant equal to 1 when $i=j$ and otherwise $0 ; \alpha_{\mathrm{L}}$ is the longitudinal dispersion; $v_{i}$ is the vector of the flow velocity in direction $i$; and $v_{j}$ is the vector of the flow velocity in direction $j$.

The equivalent density and heat capacity of rock and soil bodies follow the law of volumetric averages, namely:

$$
\begin{aligned}
& \rho_{\text {eq }}=(1-n) \rho_{\mathrm{s}}+\theta \rho_{\mathrm{w}}+(n-\theta) \rho_{\mathrm{g}} \\
& c_{\text {eq }}=(1-n) c_{\mathrm{s}}+\theta c_{\mathrm{w}}+(n-\theta) c_{\mathrm{g}}
\end{aligned}
$$

...where $\rho_{\mathrm{s}}, \rho_{\mathrm{w}}$ and $\rho_{\mathrm{g}}$ represent the density of sand, water and air; $n$ is the porosity of porous media. Under saturated condition, $q=n$, and Eq. (6) is the convective current heat transport equation in a saturated aquifer; $c_{\mathrm{s}}$ and $c_{\mathrm{g}}$ represent the specific heat capacities of soil and air, respectively.

\section{Su et al. (2016) Thermal Conductivity Model}

The thermal conductivity of soil is the key parameter for conducting heat transfer analysis in geotechnical engineering; its magnitude usually varies with the spatial distribution of the soil moisture content. The change in temperature affects both water viscosity and pore structure of the soil, which then affects the thermal process. In this regard, several thermal conductivity models have been developed. Su et al. (2016) [21] used the heat pulse method to ascertain the thermal conductivity of the undisturbed soil. By analyzing the impact of soil particle composition on thermal conductivity, the correlation between thermal conductivity and saturation, bulk density, soil particle composition, and organic matter was established, following which the $\mathrm{Su}$ et al. (2016) [21] model was proposed. In addition, Su et al. (2016) [21] compared their model with the $\mathrm{Lu}$ et al. (2007) [20] model, demonstrating that the $\mathrm{Su}$ et al. (2016) [21] model exhibits better fitting accuracy.

Both the Su et al. (2016) [21] model and the Lu et al. (2007) [20] model are based on the thermal conductivity values of dry soil $\left(\lambda_{\text {dry }}\right)$ and saturated soil $\left(\lambda_{\text {sat }}\right)$. In these models, the correlation between the thermal conductivity of the unsaturated soil $\left(\lambda_{\mathrm{eq}}\right)$ and normalized thermal conductivity $\left(K_{\mathrm{e}}\right)$ is provided by:

$$
\lambda_{\text {eq }}=\left(\lambda_{\text {sat }}-\lambda_{\text {dry }}\right) K_{\mathrm{e}}+\lambda_{\text {dry }}
$$

...where $\lambda_{\text {dry }}$ and $\lambda_{\text {sat }}$ are calculated as follows:

$$
\begin{gathered}
\lambda_{\mathrm{dry}}=-0.56 n+0.51 \\
\lambda_{\text {sat }}=\lambda_{\mathrm{s}}^{1-n} \lambda_{\mathrm{w}}^{n}
\end{gathered}
$$

...where $\lambda_{\mathrm{s}}$ is the soil thermal conductivity obtained from the quartz content $(q)$ and its thermal conductivity $\left(\lambda_{q}=7.7 \mathrm{~W} /\left(\mathrm{m}^{\circ} \mathrm{C}\right)\right)$ and the thermal conductivity of other minerals $\left(\lambda_{\mathrm{o}}\right)$, i.e., $\lambda_{\mathrm{s}}=\lambda_{\mathrm{q}}{ }^{q} \lambda_{\mathrm{q}}{ }^{1-q}$. Among them: $\lambda_{\mathrm{o}}=2.0 \mathrm{~W} /\left(\mathrm{m} \cdot{ }^{\circ} \mathrm{C}\right)(q>0.2) ; \lambda_{\mathrm{o}}=3.0 \mathrm{~W} /\left(\mathrm{m} \cdot{ }^{\circ} \mathrm{C}\right)(q \leq 0.2)$ and $\lambda_{\mathrm{w}} \mathrm{is}$ the thermal conductivity of water.

For conventional soil, the normalized thermal conductivity $K_{e}$ is:

$$
K_{\mathrm{e}}=\exp \left\{\alpha\left[1-S_{\mathrm{r}}^{(\alpha-1.33)}\right]\right\}
$$

...where $S_{\mathrm{r}}$ is the degree of saturation, 1.33 is the shape parameter, and $\alpha$ is determined by the texture of the soil and value could be provided by:

$$
\alpha=a \cdot C_{\text {clay }}+b \cdot C_{\text {silt }}+c \cdot C_{\text {sand }}+d \cdot C_{\text {om }}
$$

...where $C_{\text {clay }}, C_{\text {slit }}$ and $C_{\text {sand }}$ are the percentage values of the mass fraction of the clay, powder, and sand; $C_{\text {om }}$ is the mass ratio of the organic matter: $a, b, c$, and $d$ denote the fitting coefficients, and their values in order are considered as $-0.5863,0.9451,0.108$, and 0.0567 .

\section{Model Evaluation}

To quantitatively evaluate the simulation effect of the $\mathrm{Su}$ and $\mathrm{Lu}$ thermal conductivity models, the root mean square error (RMSE), coefficient of determination $\left(\mathrm{R}^{2}\right)$, and Nash-Sutcliffe model efficiency coefficient (NSE) 
were introduced to calculate the model's simulation accuracy as follows [27]:

$$
\begin{gathered}
\mathrm{RMSE}=\sqrt{\frac{1}{n} \sum_{i=1}^{n}\left(M_{i}-S_{i}\right)^{2}} \\
\mathrm{R}^{2}=\frac{\left[\sum_{i=1}^{n}\left(M_{i}-\bar{M}\right)\left(S_{i}-\bar{S}\right)^{2}\right]}{\sum_{i=1}^{n}\left(M_{i}-\bar{M}\right)^{2} \sum_{i=1}^{n}\left(S_{i}-\bar{S}\right)^{2}} \\
\mathrm{NSE}=1-\frac{\sum_{i=1}^{n}\left(M_{i}-S_{i}\right)^{2}}{\sum_{i=1}^{n}\left(M_{i}-\bar{M}\right)^{2}}
\end{gathered}
$$

...where $M_{i}$ and $S_{i}$ in order denote the observed and simulated temperature values; $\bar{M}$ is the mean value of the observed temperature; and $n$ is the number of observations. The range of RMSE is $(0,+\infty)$, which signifies the degree of dispersion of the sample. In addition, lower the deviation between the simulated values and the observed one, smaller the value of RMSE. The closer the decision coefficient $\mathrm{R}^{2}$ is to 1 , the better the model's goodness of fit is; for values $>0.5$, the simulated results could be considered as acceptable. The value of NSE varies in the range of $-\infty$ to 1.0. The NSE, which ranges from -1 to 1 can be used as a criterion to assess the predictive power of hydro-thermal coupling models. A perfect match of the simulated data and the observed data is represented by NSE $=1.0$, and the NSE value $>0.6$ could be considered good, while its zero value represents estimations/forecasts no better than taking the average of the observed data, while values lower than zero represent an increasingly poor model from the performance perspective [28].

\section{Initial and Boundary Conditions}

Based on the numerical model and the field measurement data, as well as the assumption that no flow and transport occur longitudinally to the canal. A $2 \mathrm{D}$ vertical transect model was constructed. Notably, in the current research on the riparian hyporheic exchange using the heat tracing method, most studies adopted the 2D conceptual model [12, 23, 29-31]. Chen et al. (2015) [32] compared the hyporheic exchange and associated metrics of $2 \mathrm{D}$ and $3 \mathrm{D}$ bedforms, suggesting that a $2 \mathrm{D}$ idealization is a reasonable approximation for the more complex 3D situation if local details are insignificant. One transverse section was only considered for analysis to simplify the research problem.

In this study, the COMSOL Multiphysics software was exploited to modify the relevant modules to attain the finite element solution of the coupled model for the saturated-unsaturated seepage field, as well as the temperature field, in the riparian zone. Fig. 1 shows a schematic plot of the hydro-thermal simulations of the computational region of the river-water infiltration soil. Based on the difference in soil permeability, the soil types in the solution zone could be categorized into Zone 1 and Zone 2 (Fig. 1). For the saturated-unsaturated seepage field, the left and right boundaries (AF and $\mathrm{BC})$ were set to be as a no-flow boundary; the bottom boundary (AB) was assumed to be a permeable one. In addition, groundwater recharge and lateral flow were achieved by setting the ED boundary in the model to a variable head boundary condition, which was attained by defining a cubic spline interpolation function in the COMSOL Multiphysics software. The initial pressure head was set equal to $0 \mathrm{~m}$. For the temperature field, the left, right, and bottom boundaries (AF, BC, and $\mathrm{AB}$ ) of the spatial domain were subjected to the adiabatic condition; the atmospheric contact boundaries (EF and $\mathrm{CD})$ were set to be an atmospheric boundary, and the water-soil contact boundary (ED) was set as the water temperature boundary. The initial temperature field was set by the initial average value, which was observed by the sensor. The initial temperatures at Zones 1 and 2 in order were set equal to $6^{\circ} \mathrm{C}$ and $5^{\circ} \mathrm{C}$.

\section{Input Parameters}

With regard to the relevant literature, Table 1 shows computational parameters for both seepage and temperature fields of the numerical model. The values of the saturated-unsaturated hydraulic parameters and thermal characteristics parameters are provided according to Naranjo and Smith (2016) [23] and He et al. (2017) [33]. The thermal dispersion was taken as 0.01 ; the thermal conductivity values of the water and air were considered to be 0.58 and $0.024 \mathrm{~W} /\left(\mathrm{m} \cdot{ }^{\circ} \mathrm{C}\right)$, respectively; the specific heat capacity of the soil was equal to $410 \mathrm{~J} /\left(\mathrm{kg} \cdot{ }^{\circ} \mathrm{C}\right)$; for the water and air media, the values of specific heat capacity in order were set equal to 4186 and $1005 \mathrm{~J} /\left(\mathrm{kg}^{\circ}{ }^{\circ} \mathrm{C}\right)$, whereas their densities were 1000 and $1.025 \mathrm{~kg} / \mathrm{m}^{3}$, respectively. Table 2 presents the original sediment matter group at the central position of the cross-section.

\section{Results}

\section{Model Validation and Comparative Analysis}

Fig. 2 presents the comparison between the simulated and measured values of the riparian zone temperature attained by using the $\mathrm{Su}$ et al. (2016) [21] thermal conductivity model and the Lu et al. (2007) [20] thermal conductivity model. The consistency of the two models was evaluated their by using the three model indicators. Table 3 presents the root mean square error (RMSE), coefficient of determination $\left(\mathrm{R}^{2}\right)$, and NashSutcliffe model efficiency coefficient (NSE) evaluated by the two thermal conductivity models. The value of the RMSE obtained by the Su et al. (2016) [21] thermal 
Table 1. Calculation of the parameters of the transient heat transfer in the riparian zone.

\begin{tabular}{|c|c|c|c|c|}
\hline Parameters & Symbol & Units & Zone & Value \\
\hline \multirow{2}{*}{ Horizontal hydraulic conductivity } & \multirow{2}{*}{$K_{\mathrm{h}}$} & \multirow{2}{*}{$\mathrm{m} / \mathrm{s}$} & 1 & $7.178 \times 10^{-6}$ \\
\hline & & & 2 & $7.178 \times 10^{-6}$ \\
\hline \multirow{2}{*}{ Vertical hydraulic conductivity } & \multirow{2}{*}{$K_{\mathrm{v}}$} & \multirow{2}{*}{$\mathrm{m} / \mathrm{s}$} & 1 & $6.622 \times 10^{-4}$ \\
\hline & & & 2 & $6.167 \times 10^{-5}$ \\
\hline \multirow{2}{*}{ Porosity } & \multirow{2}{*}{$n$} & \multirow{2}{*}{$\%$} & 1 & 41 \\
\hline & & & 2 & 41 \\
\hline \multirow{2}{*}{ Saturated moisture content } & \multirow{2}{*}{$\theta_{\mathrm{s}}$} & \multirow{2}{*}{$\mathrm{m}^{3} / \mathrm{m}^{3}$} & 1 & 0.43 \\
\hline & & & 2 & 0.43 \\
\hline \multirow{2}{*}{ Residual moisture content } & \multirow{2}{*}{$\theta_{\mathrm{r}}$} & \multirow{2}{*}{$\mathrm{m}^{3} / \mathrm{m}^{3}$} & 1 & 0.057 \\
\hline & & & 2 & 0.057 \\
\hline \multirow{2}{*}{ Van Genuchten Alpha } & \multirow{2}{*}{$\alpha$} & \multirow{2}{*}{$\mathrm{m}^{-1}$} & 1 & 12.4 \\
\hline & & & 2 & 12.4 \\
\hline \multirow{2}{*}{ Van Genuchten Beta } & \multirow{2}{*}{$\beta$} & \multirow{2}{*}{-} & 1 & 2.28 \\
\hline & & & 2 & 2.28 \\
\hline \multirow{2}{*}{ Longitudinal dispersion } & \multirow{2}{*}{$\alpha_{\mathrm{L}}$} & \multirow{2}{*}{$\mathrm{m}$} & 1 & 0.01 \\
\hline & & & 2 & 0.01 \\
\hline \multirow{2}{*}{ Transverse dispersion } & \multirow{2}{*}{$\alpha_{\mathrm{T}}$} & \multirow{2}{*}{$\mathrm{m}$} & 1 & 0.01 \\
\hline & & & 2 & 0.01 \\
\hline \multirow{2}{*}{ Quartz } & \multirow{2}{*}{$q$} & \multirow{2}{*}{$\%$} & 1 & 54 \\
\hline & & & 2 & 20 \\
\hline \multirow{2}{*}{ Elastic water storage rate } & \multirow{2}{*}{$S_{\mathrm{s}}$} & $1 / \mathrm{Pa}$ & 1 & $10^{-6}$ \\
\hline & & $1 / \mathrm{Pa}$ & 2 & $10^{-6}$ \\
\hline
\end{tabular}

Table 2. The soil texture of the undisturbed soil core at the center of the channel monitoring section (source: Naranjo and Smith (2016)).

\begin{tabular}{|c|c|c|c|c|c|}
\hline $\begin{array}{c}\text { Depth of core interval } \\
(\mathrm{cm})\end{array}$ & $\begin{array}{c}\text { Organic matter } \\
(\mathrm{g} / \mathrm{kg})\end{array}$ & $\begin{array}{c}\text { Sand } \\
(\%)\end{array}$ & $\begin{array}{c}\text { Slit } \\
(\%)\end{array}$ & $\begin{array}{c}\text { Clay } \\
(\%)\end{array}$ & $\begin{array}{c}\text { Textural } \\
\text { classification }\end{array}$ \\
\hline $0 \sim 7.5$ & 10 & 72 & 7 & 21 & Sandy clay \\
\hline $7.5 \sim 15$ & 10 & 68 & 11 & 21 & Sandy clay \\
\hline $15 \sim 45$ & 20 & 18 & 26 & 56 & Clay \\
\hline
\end{tabular}

conductivity model varied from $1.41^{\circ} \mathrm{C}$ to $2.73^{\circ} \mathrm{C}$ (average: $1.95^{\circ} \mathrm{C}$; Table 3). The deviation between the simulated value and the measured value was relatively small. The $\mathrm{R}^{2}$ values varied from 0.71 to 0.95 (average: 0.89 ), and all $\mathrm{R}^{2}$ values were $>0.5$, suggesting that the simulated results could be considered as acceptable, and its value was closer to 1 , suggesting that the model fits well. The NSE value varied from 0.62 to 0.93 , and all monitoring points were $>0.6$, suggesting that the measured and simulated values matched well. However, the RMSE value obtained by the $\mathrm{Lu}$ et al. (2007) [20] thermal conductivity model simulation ranged $1.46^{\circ} \mathrm{C}$ to $7.00^{\circ} \mathrm{C}$ (average: $3.58^{\circ} \mathrm{C}$ ). The RMSE value was higher at T2-2.75 m, suggesting that the simulation error was larger than others. The $\mathrm{R}^{2}$ value varied from 0.55 to 0.99 (average: 0.87). Although the $\mathrm{R}^{2}$ value at some monitoring points was better than the simulation results of the Su et al. (2016) [21] model, the overall effect of the $\mathrm{Su}$ et al. (2016) [21] model was better. In addition, from the perspective of NSE value obtained by $\mathrm{Lu}$ et al. (2007) [20] simulation, only 50\% of the monitoring points had a value $>0.6$, which is notably worse than the simulation results of the Su et al. (2016) [21] model.

The analysis mentioned above revealed that no matter which evaluation index is used, the simulation results of the riparian zone temperature based on the $\mathrm{Su}$ 

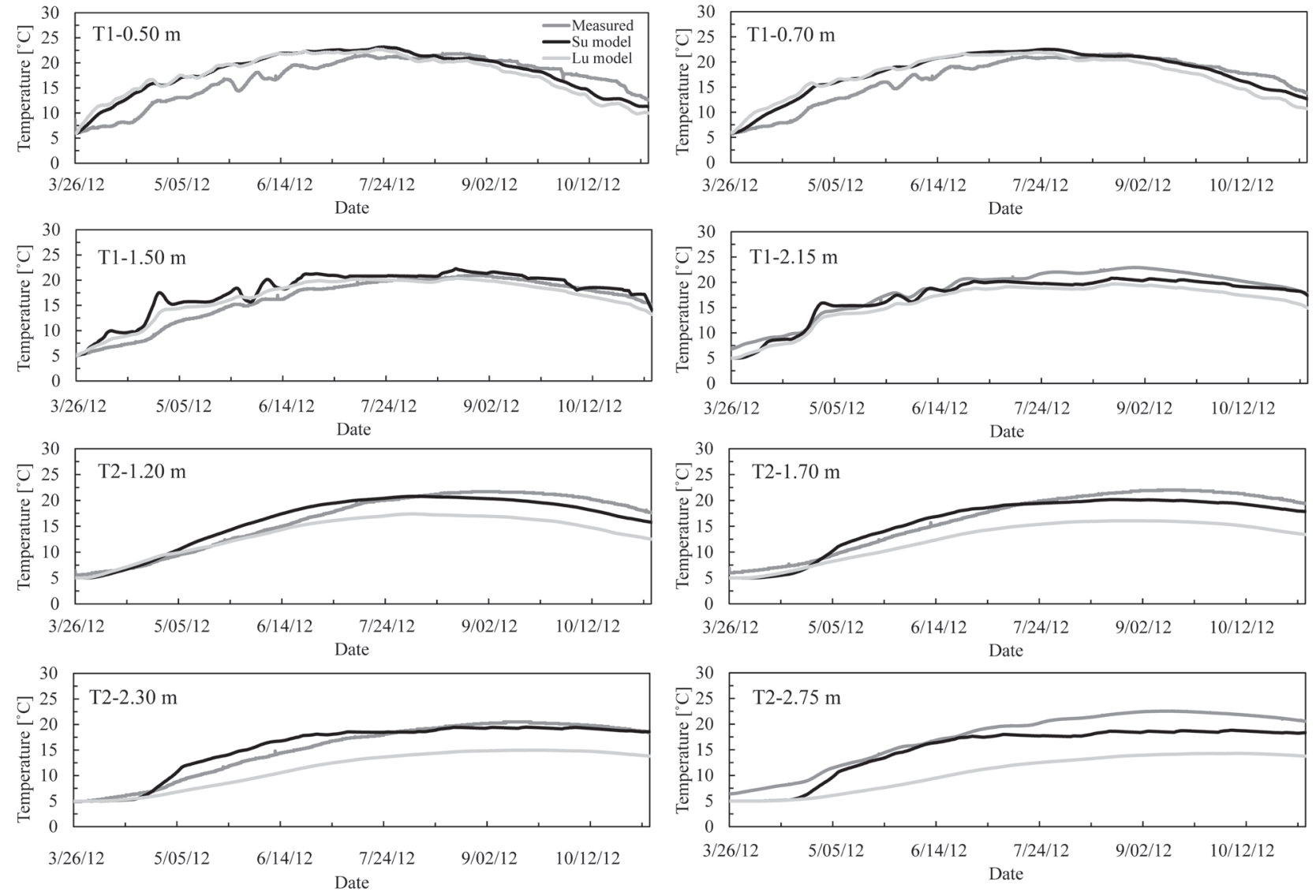

Fig. 2. Comparison of the measured and simulated temperature time series at different observation points. Green line, the measured temperature data; blue and red lines, the temperature data simulated by Su et al. (2016) thermal conductivity model and Lu et al. (2007) thermal conductivity model, respectively.

Table 3. The root mean square error (RMSE; $\left.{ }^{\circ} \mathrm{C}\right)$, coefficient of determination $\left(\mathrm{R}^{2}\right)$, and NashSutcliffe model efficiency coefficient (NSE) values for $\mathrm{Su}$ and $\mathrm{Lu}$ models simulation results.

\begin{tabular}{|c|c|c|c|c|c|c|c|}
\hline \multicolumn{2}{|c|}{ Temperature sensors } & \multicolumn{3}{|c|}{ Su et al. (2016) model } & \multicolumn{3}{c|}{ Lu et al. (2007) model } \\
\cline { 2 - 9 } \multicolumn{1}{|c|}{} & RMSE $\left({ }^{\circ} \mathrm{C}\right)$ & $\mathrm{R}^{2}$ & NSE & RMSE $\left({ }^{\circ} \mathrm{C}\right)$ & $\mathrm{R}^{2}$ & NSE \\
\hline \multirow{3}{*}{$\mathrm{T} 1$} & $0.50 \mathrm{~m}$ & 2.73 & 0.71 & 0.62 & 3.20 & 0.55 & 0.48 \\
\cline { 2 - 9 } & $0.70 \mathrm{~m}$ & 2.18 & 0.83 & 0.77 & 2.76 & 0.65 & 0.63 \\
\cline { 2 - 9 } & $1.50 \mathrm{~m}$ & 2.21 & 0.92 & 0.76 & 1.46 & 0.92 & 0.90 \\
\cline { 2 - 9 } & $2.15 \mathrm{~m}$ & 1.41 & 0.95 & 0.90 & 2.40 & 0.98 & 0.71 \\
\hline \multirow{3}{*}{$\mathrm{T} 2$} & $1.20 \mathrm{~m}$ & 1.55 & 0.92 & 0.92 & 3.39 & 0.90 & 0.60 \\
\cline { 2 - 9 } & $1.70 \mathrm{~m}$ & 1.48 & 0.93 & 0.93 & 4.30 & 0.98 & 0.38 \\
\cline { 2 - 9 } & $2.30 \mathrm{~m}$ & 1.39 & 0.94 & 0.93 & 4.12 & 0.99 & 0.37 \\
\cline { 2 - 9 } & $2.75 \mathrm{~m}$ & 2.63 & 0.95 & 0.74 & 7.00 & 0.96 & -0.83 \\
\hline
\end{tabular}

et al. (2016) [21] model are better than those of the $\mathrm{Lu}$ et al. (2007) [20] model. Thus, in the following studies, the Su et al. (2016) [21] model was used to assess the riparian temperature variation characteristics and the lateral hyporheic exchange recharge pattern.

The seepage law was simulated for a given water level by the hydro-thermal coupling model based on the $\mathrm{Su}$ et al. (2016) [21] model to further validate the accuracy and applicability of the Su et al. (2016) [21] model in describing the hydro-thermal dynamic process of the riparian zone. Fig. 3 presents the measured water level and the simulated seepage from the prediction period (March 26, 2012 November 4, 2012). The riparian zone seepage velocity primarily correlated with the head variation, and the seepage law was consistent with the Ren et al. (2019) [13] research 


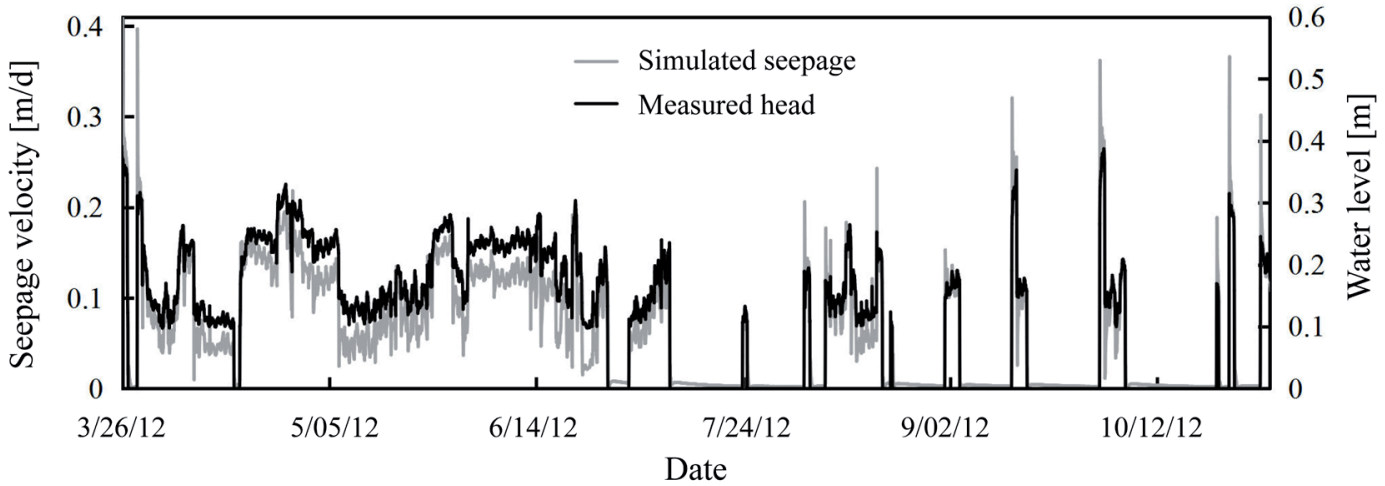

Fig. 3. Measured head and simulated seepage during the prediction period (March 26, 2012November 4, 2012).

work. The simulated seepage velocity of the riparian zone could be considered as the rate of the hyporheic exchange whose value in the riparian zone closely correlated with the dynamic change of the water level, and, to some extent, it has a consistent variation trend.

\section{Simulation of Temperature Distribution and Lateral Hyporheic Exchange Pattern in the Riparian Zone}

Four different times (i.e., $\mathrm{t}=2: 00,8: 00,14: 00$, and 20:00) were considered on July 6, 2012 (Summer), September 15, 2012 (transitional season), and November 2, 2012 (Winter) to further elucidate the spatial distribution of the temperature in the riparian section and the dynamic characteristics of the diurnal variation and seasonality. The daily diurnal variation of temperature was compared and analyzed in the riparian zone in different seasons using the calibrated numerical model (Fig. 4). To intuitively obtain the temperature distribution of the riparian zone and include all the measurement points in the $\mathrm{T} 1$ and $\mathrm{T} 2$ temperature monitoring rods, the study area was limited to within $-5.177 \mathrm{~m} \leq \mathrm{x} \leq 5.133 \mathrm{~m}$ and $-2.5 \mathrm{~m} \leq \mathrm{y} \leq 1.438 \mathrm{~m}$ within the area indicated by blue dotted lines in Fig. 1.

The spatial distribution of the temperature in the aquifer of the riparian zone was not uniform and changed with time (Fig. 4). Based on the comparison between the obtained results for the abovementioned four times in a day (Fig. 4a-c), founded that the temperature of the riparian zone varied marginally; the primary reason for this fact is that the soil temperature of soils beyond $1-\mathrm{m}$ depth is usually insensitive to the diurnal cycle of the air temperature. Recent studies reported that solar radiation and the annual temperature fluctuation extends to a depth of about $10 \mathrm{~m}$ [34, 35]. In addition, Engelhardt et al. (2011) [36] reported that diurnal temperature fluctuations could not be retrieved within the deeper HZ, which was then established by Lee et al. (2013) [37]. Based on the selected

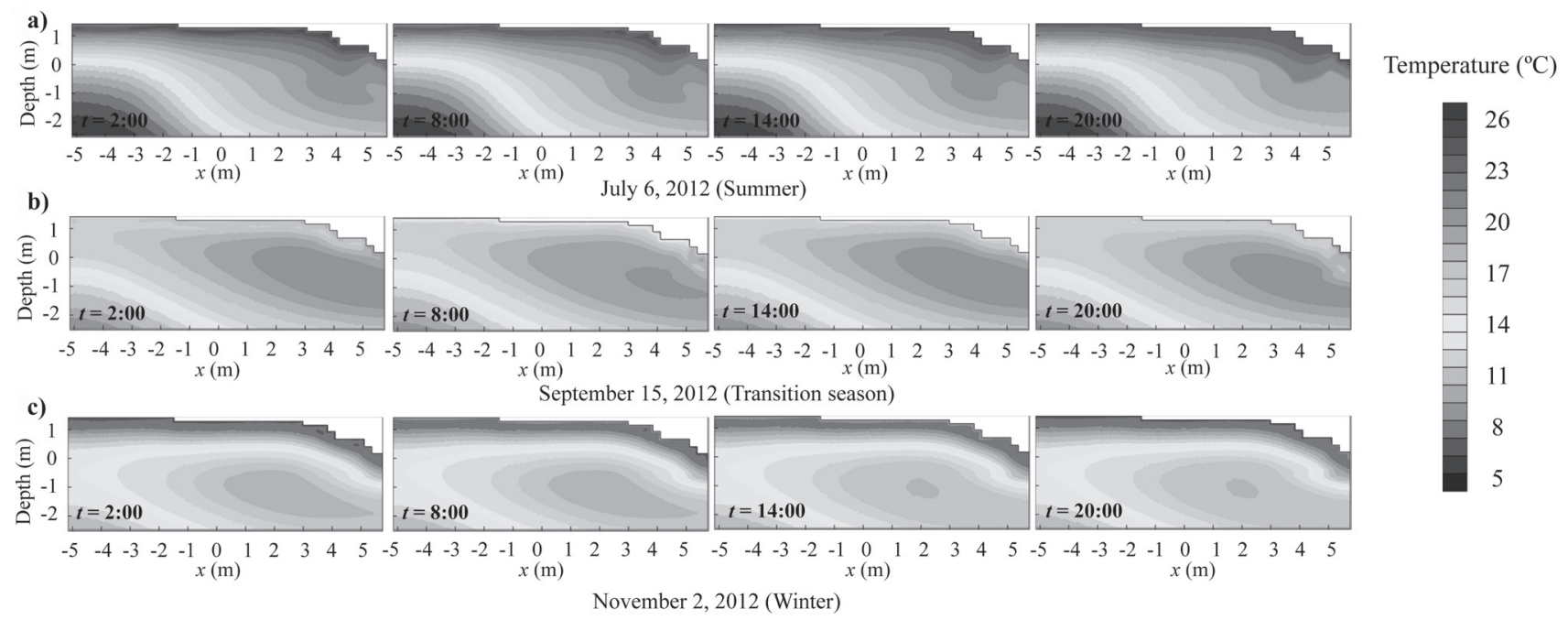

Fig. 4 .The characteristics of the temperature distribution in the riparian zone at different times: a) July 2, 2012 (Summer); b) September 3, 2012 (Transition season); c) November 3, 2012 (Winter). The four temperature clouds for each row correspond to four different moments of the day, namely 2:00 am, 8:00 am, 2:00 pm, and 8:00 pm. 


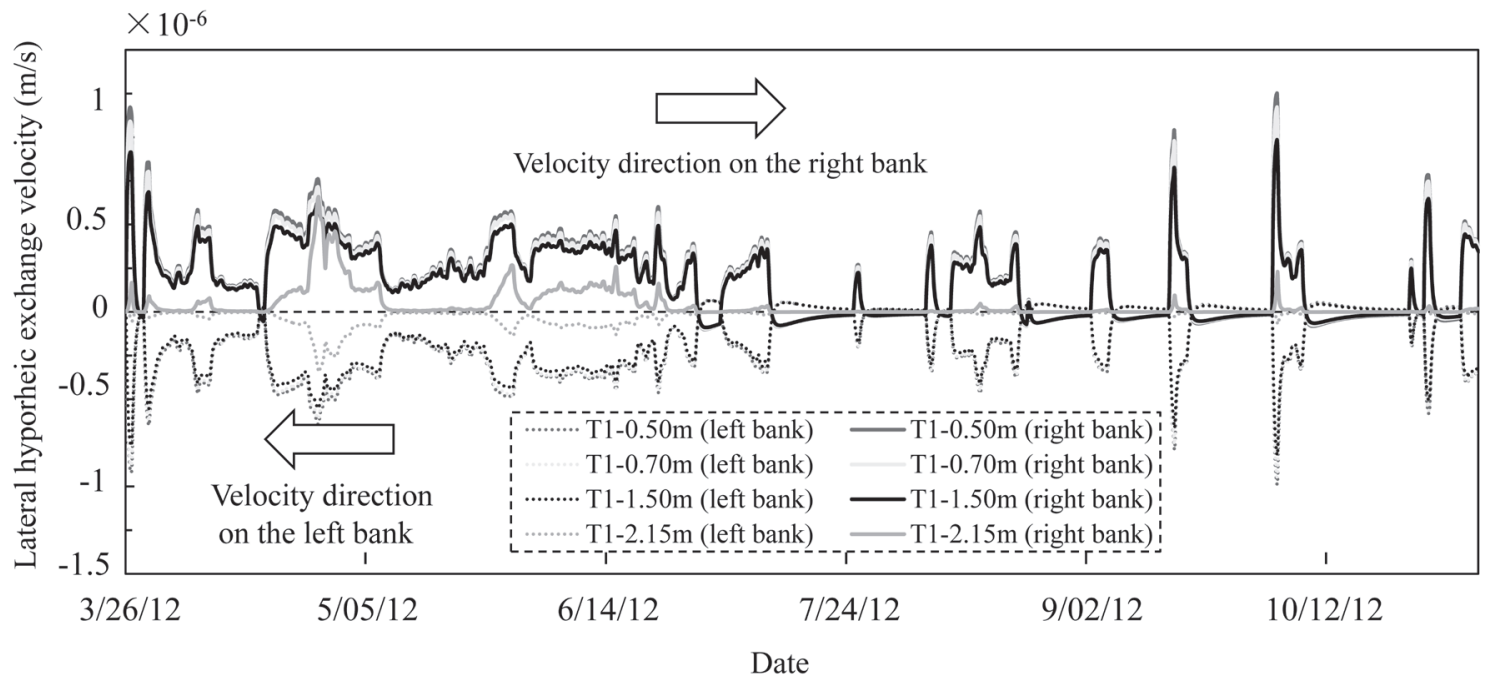

Fig. 5. The seepage velocity of the monitoring points on both sides of the river.

research area, which is about $0.752 \sim 3.938 \mathrm{~m}$ below the surface $(-2.5 \mathrm{~m} \leq \mathrm{y} \leq 1.438 \mathrm{~m})$, the unclear change in the temperature cloud at four times in the Summer, transition season and Winter could be interpreted as shown in Fig. 4. Regarding the daily variation, the seasonal variation (primarily refers to the variations of temperature and water level) exerts more impact on the temperature distribution of the riparian zone. The plotted results confirmed that the temperature decreases with sediment depth in the riparian zone in the Summer but increases in the Winter.

There exist mainly three relationships for the lateral hyporheic exchange between the river and the riparian zone: (1) water flows from the riparian zone to the river; (2) water flows from the river to the riparian zone; and (3) water flows from the riparian zone to the river and then to the riparian zone. To identify the pattern of the hyporheic exchange in the riparian zone, other four monitoring points were set on the right bank of the riparian zone model to identify the pattern of the hyporheic exchange in the riparian zone. The recharge pattern of the hyporheic exchange could be distinguished by the direction of the seepage velocity at the monitoring points on both sides of the river.
Fig. 5 displays the seepage velocity of the monitoring points on both sides of the river; the seepage velocity of the left bank monitoring point is negative during the study period, while that of the right bank is positive, suggesting that the river water recharges groundwater to both sides of the river bank.

\section{Sensitivity to Hydro-Thermal Coupling Model Parameters}

Several uncertainties exist in the hydro-thermal coupling modeling of the riparian zone such as multiple parameters, scale diversification of the model parameters, and systematic errors. Thus, the uncertainty and the sensitivity analysis of the model parameters could effectively extend our knowledge regarding the influential factors on the output variables, as well as the interactional role of parameters on the results [38]. Through a quantitative study of the impact of each factor on the attained results, it was determined that the main factors were controlled the variation of the temperature field. Currently, the Morris sensitivity analysis is extensively used in engineering and is considered to be a more reliable and simple global

Table 4. The probability distribution of the riparian zone's parameters using the hydro-thermal coupling model.

\begin{tabular}{|c|c|c|c|}
\hline Parameters & Symbol & Units & Parameter-observed probability distribution \\
\hline Heat capacity of solids & $c_{\mathrm{s}}$ & $\mathrm{J} /\left(\mathrm{kg} \cdot{ }^{\circ} \mathrm{C}\right)$ & $c_{\mathrm{s}} \sim \mathrm{U}(373,485)$ \\
\hline Saturated moisture content & $\theta_{\mathrm{s}}$ & $\mathrm{m}^{3} / \mathrm{m}^{3}$ & $\theta_{\mathrm{s}} \sim \mathrm{U}(0.25,0.60)$ \\
\hline Residual moisture content & $\theta_{\mathrm{r}}$ & $\mathrm{m}^{3} / \mathrm{m}^{3}$ & $\theta_{\mathrm{r}} \sim \mathrm{U}(0.034,0.1)$ \\
\hline Hydraulic conductivity & $K_{\mathrm{s}}$ & $\mathrm{m} / \mathrm{s}$ & $K_{\mathrm{s}} \sim \mathrm{U}\left(2.778 \times 10^{-8}, 2.778 \times 10^{-3}\right)$ \\
\hline Porosity & $n$ & - & $n \sim \mathrm{U}(0.3,0.45)$ \\
\hline van Genuchten Alpha & $\alpha$ & $\mathrm{m}^{-1}$ & $\alpha \sim \mathrm{U}(2,14.5)$ \\
\hline van Genuchten Beta & $\beta$ & - & $\beta \sim \mathrm{U}(1.4,2.6)$ \\
\hline
\end{tabular}


Table 5. A sample of the parameters of the riparian zone based on the hydro-thermal coupling model.

\begin{tabular}{|c|c|}
\hline Sample & Trajectory 1 \\
\hline 1 & $\left(437,0.30,0.081,2.381 \times 10^{-3}, 0.364,2.00,1.74\right)$ \\
\hline 2 & $\left(437,0.30,0.081,2.778 \times 10^{-3}, 0.364,2.00,1.74\right)$ \\
\hline 3 & $\left(437,0.30,0.081,2.778 \times 10^{-3}, 0.364,2.00,1.91\right)$ \\
\hline 4 & $\left(453,0.30,0.081,2.778 \times 10^{-3}, 0.364,2.00,1.91\right)$ \\
\hline 5 & $\left(453,0.30,0.081,2.778 \times 10^{-3}, 0.343,2.00,1.91\right)$ \\
\hline 6 & $\left(453,0.30,0.072,2.778 \times 10^{-3}, 0.343,2.00,1.91\right)$ \\
\hline 7 & $\left(453,0.30,0.072,2.778 \times 10^{-3}, 0.343,3.79,1.91\right)$ \\
\hline 8 & $\left(453,0.35,0.072,2.778 \times 10^{-3}, 0.343,3.79,1.91\right)$ \\
\hline
\end{tabular}

sensitivity analysis method. Thus, in the following studies, the Morris method was used, as described in Feng et al. (2018) [39].

Based on the given parameter range by Naranjo and Smith (2016) [23], it was assumed that the parameters of the riparian zone hydro-thermal coupling model would conform to the uniform distribution of Table 4.

Based on the test principle of the Morris method, sampling samples of hydro-thermal coupling model parameters $\left(c_{s}, \theta_{s}, \theta_{r}, K, n, \alpha, b\right)$ of 80 groups of the riparian zone were obtained by sampling 10 trajectories at eight levels. $X_{i, j}(\mathrm{i}=1, \cdots, 10 ; \mathrm{j}=1, \cdots, 8)$ represent the results of the sampling of the trajectory $i$ and the vector $\mathrm{j}$. Table 5 presents the list of the obtained results for the first trajectory, but the other nine trajectories are not listed.

With the other parameters unchanged, the sample vectors from 80 sample groups were substituted into the COMSOL Multiphysics software, and the temperature changes at different monitoring points in the hydrothermal coupling model of the riparian zone were calculated. Eight monitoring points, whose coordinates were $1^{\#}(4.2,0.186), 2^{\#}(4.2,0.014), 3^{\#}(4.2,-0.814)$, $4^{\#}(4.2,-1.464), 5^{\#}(1.2,0.105), 6^{\#}(1.2,-0.395), 7^{\#}$ $(1.2,-0.995)$, and $8^{\#}(1.2,-1.445)$, corresponded to different depths of $\mathrm{T} 1$ and $\mathrm{T} 2$ temperature rods and are considered along the riparian zone. Considering trajectory 1 as an example, Table 6 lists changes in the computed temperature of eight monitoring points using numerical simulation.

After the numerical simulation of 80 groups of parameters, the temperature values of eight monitoring points were evaluated under each group of parameters. Then, the mean value $(m)$ and the standard deviation $(s)$ of the seven parameters were calculated based on the test steps of the Morris method. Table 7 presents $m$ and $s$ of each parameter affected by the temperature in the eight monitoring points at the $5352^{\text {nd }}$ time step. The absolute value of in Table 7 was drawn as the scatter plot (Fig. 6) to compare the influential factors of each point on the temperature value of the model.

Based on Table 7 and Fig. 6, it was found that the values of $\mu$ and $\sigma$ for all eight monitoring points were different. In addition, some variation rules were valid for them - the influence of the parameters on the temperature values exhibited a decreasing trend along the depth direction of the riparian zone (from monitoring point 1 to monitoring point 4; from monitoring point 5 to monitoring point 8). Moreover, the interactions of each parameter affecting the

Table 6. Monitoring points temperature of the riparian zone's parameters using the hydro-thermal model parameters.

\begin{tabular}{|c|c|c|c|c|c|c|c|c|}
\hline \multirow{2}{*}{ Sample } & \multicolumn{9}{|c|}{ Temperature value of each monitoring point $/{ }^{\circ} \mathrm{C}$} \\
\cline { 2 - 10 } & $1^{\#}$ & $2^{\#}$ & $3^{\#}$ & $4^{\#}$ & $5^{\#}$ & $6^{\#}$ & $7^{\#}$ & $8^{\#}$ \\
\hline 1 & 19.53 & 19.52 & 19.07 & 18.76 & 20.58 & 20.59 & 20.13 & 19.85 \\
\hline 2 & 19.75 & 19.74 & 19.22 & 18.85 & 20.74 & 20.73 & 20.25 & 19.95 \\
\hline 3 & 19.88 & 19.83 & 19.22 & 18.82 & 20.93 & 20.82 & 20.27 & 19.95 \\
\hline 4 & 19.89 & 19.83 & 19.22 & 18.82 & 20.93 & 20.82 & 20.28 & 19.97 \\
\hline 5 & 19.92 & 19.87 & 19.25 & 18.83 & 20.94 & 20.82 & 20.27 & 19.96 \\
\hline 6 & 19.90 & 19.85 & 19.24 & 18.84 & 20.95 & 20.85 & 20.30 & 19.98 \\
\hline 7 & 19.37 & 19.57 & 19.27 & 18.89 & 20.33 & 20.54 & 20.17 & 19.92 \\
\hline 8 & 19.40 & 19.59 & 19.27 & 18.87 & 20.36 & 20.55 & 20.17 & 19.90 \\
\hline
\end{tabular}


Table 7. Morris test results of the monitoring points in the riparian zone using the hydro-thermal coupling model.

\begin{tabular}{|c|c|c|c|c|c|c|c|c|c|}
\hline \multirow{2}{*}{$\begin{array}{l}\text { Morris } \\
\text { index }\end{array}$} & \multirow{2}{*}{ Parameters } & \multicolumn{8}{|c|}{ Monitoring results } \\
\hline & & $1^{\#}$ & $2^{\#}$ & $3^{\#}$ & $4^{\#}$ & $5^{\#}$ & $6^{\#}$ & $7^{\#}$ & $8^{\#}$ \\
\hline \multirow{7}{*}{$\mu$} & $c_{\mathrm{s}}$ & 0.119 & 0.105 & 0.077 & 0.049 & 0.126 & 0.189 & 0.182 & 0.168 \\
\hline & $\theta_{\mathrm{s}}$ & 0.140 & 0.147 & 0.119 & 0.091 & 0.210 & 0.238 & 0.210 & 0.182 \\
\hline & $\theta_{\mathrm{r}}$ & -0.056 & -0.077 & -0.063 & -0.021 & -0.035 & -0.084 & -0.084 & 0.098 \\
\hline & $K_{\mathrm{s}}$ & 1.197 & 1.414 & 1.057 & 0.630 & 1.701 & 1.645 & 1.337 & 1.162 \\
\hline & $n$ & -0.007 & -0.049 & -0.042 & -0.028 & -0.077 & -0.056 & 0.000 & 0.007 \\
\hline & $\alpha$ & -1.351 & -0.651 & 0.147 & 0.147 & -1.995 & -1.043 & -0.413 & -0.378 \\
\hline & $\beta$ & 0.392 & 0.294 & 0.056 & -0.028 & 0.602 & 0.364 & 0.168 & 0.147 \\
\hline \multirow{7}{*}{$\sigma$} & $c_{\mathrm{s}}$ & 0.353 & 0.405 & 0.339 & 0.215 & 0.604 & 0.675 & 0.609 & 0.550 \\
\hline & $\theta_{\mathrm{s}}$ & 0.094 & 0.115 & 0.104 & 0.121 & 0.143 & 0.137 & 0.133 & 0.169 \\
\hline & $\theta_{\mathrm{r}}$ & 0.200 & 0.218 & 0.202 & 0.109 & 0.196 & 0.207 & 0.174 & 0.605 \\
\hline & $K_{\mathrm{s}}$ & 1.393 & 0.798 & 0.411 & 0.367 & 1.837 & 1.024 & 0.537 & 0.501 \\
\hline & $n$ & 0.181 & 0.234 & 0.220 & 0.114 & 0.066 & 0.082 & 0.070 & 0.106 \\
\hline & $\alpha$ & 0.582 & 0.542 & 0.167 & 0.127 & 0.637 & 0.606 & 0.488 & 0.689 \\
\hline & $\beta$ & 0.432 & 0.285 & 0.159 & 0.109 & 0.586 & 0.310 & 0.196 & 0.209 \\
\hline
\end{tabular}

temperature with other ones led to a decreasing trend. A comparison between the monitoring points on $\mathrm{T} 1$ temperature rod and those on $\mathrm{T} 2$ temperature rod revealed that the temperature values far from the monitoring points (No. 5-8) were more affected by the parameters than those close to the monitoring points (No. 1-4). Furthermore, the interactions between the parameters resulted in an increasing trend.

Although $\mu$ of eight monitoring points varied with the location, $\mu$ of the hydraulic conductivity $\left(K_{\mathrm{s}}\right)$ was generally large, which exerted a substantial impact on the output of the model temperature. Regarding a specific value of the heat capacity $\left(c_{\mathrm{s}}\right)$, the porosity $(n)$, the residual water content $\left(\theta_{\mathrm{r}}\right)$, the saturated water content $\left(\theta_{\mathrm{s}}\right)$, and the van Genuchten model parameters $(\alpha, \beta)$, the corresponding would be small; such a value belongs to the small sensitive parameters and exerts marginal impact on the model outputs. In addition, $\mu$ of the porosity $(n)$ and the residual water content $\left(\theta_{\mathrm{r}}\right)$ were close to zero, which exerted a little impact on the model outputs, suggesting that the effects of the porosity and residual water content on the temperature

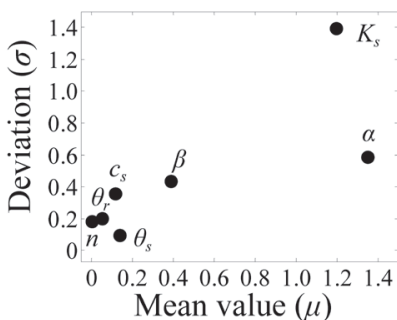

(a) $1^{\#}$

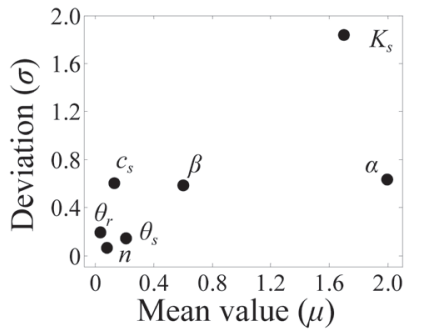

(e) $5^{\#}$

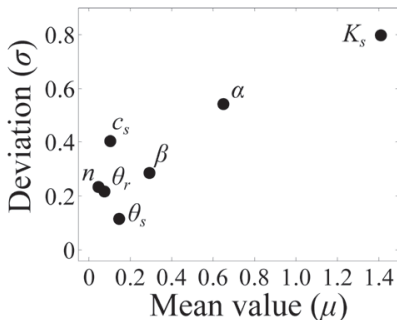

(b) $2^{\#}$

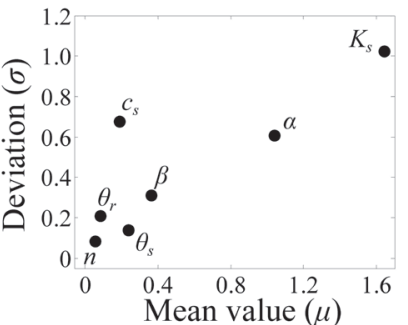

(f) $6^{\#}$

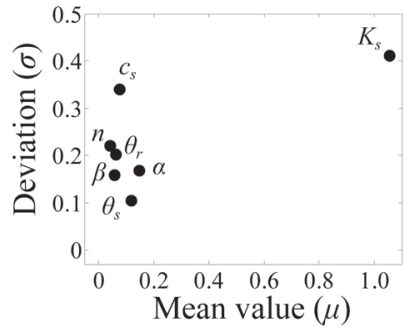

(c) $3^{\#}$

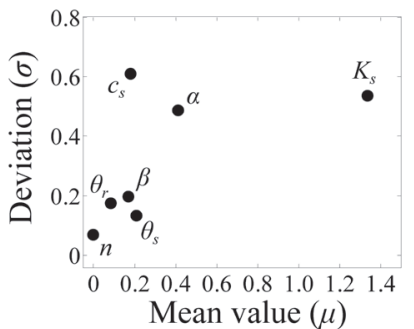

(g) $7^{\#}$

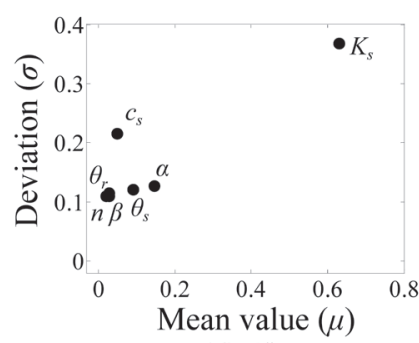

(d) $4^{\#}$

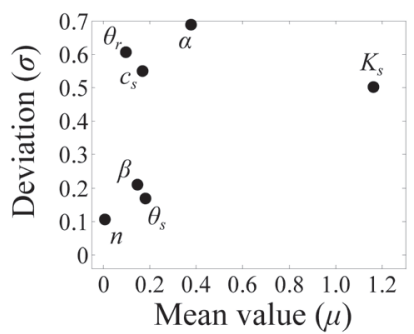

(h) $8^{\#}$

Fig. 6. Morris test results of the No. 1-8 monitoring points. 
of the riparian zone could be neglected in the process of the heat conduction. The value $s$ of the hydraulic conductivity $\left(K_{\mathrm{s}}\right)$ was large (Fig. 6); in other words, when it affects the outputs of the model temperature, it exhibits a significant interaction with other factors, or their impact on the output temperature would be nonlinear. Furthermore, the value of $\mu$ was large, and the corresponding $\sigma$ was generally large, suggesting that higher the influence of a parameter on the output value, higher the interaction with other parameters.

Based on the results mentioned above, the hydraulic conductivity $\left(K_{\mathrm{s}}\right)$ is the critical factor affecting the temperature output of the model, which is why the hydraulic conductivity is the volume of water at the existing kinematic viscosity that moves in unit time through a unit area of the saturated substrates [40]. In the interaction between the surface water and the groundwater, the hydraulic conductivity of the $\mathrm{HZ}$ directly affects the infiltration of the river into the aquifer, as well as the discharge of the aquifer to the river. Typically, hydraulic conductivity was used to measure the recharge capacities of both surface water and groundwater. In addition, the temporal variation of hydraulic conductivity in the HZ could directly affect the temporal variability of the water exchange, energy transfer, and spatial distribution patterns of the surface water and the groundwater in rivers [41]. Meanwhile, further studies revealed that hydraulic conductivity is the major cause of the water movement through the substrate [42]. Delfs et al. (2009) [43] conducted a sensitivity analysis on several parameters in the Richards equation, and reported that the soil hydraulic conductivity exerts the highest impact on the surface runoff.

The impact of each parameter on the model temperature exhibited positive and the negative effects (Table 7). The positive-negative relationship could provide some references for the model calibration. The positive relationship revealed that an increasing and decreasing of the parameters corroborated with the temperature variation in the process of the parameter adjustment. However, the negative relationship displayed that an increasing and decreasing of parameters were against the temperature variation. Based on this study, when the simulated temperature of the riparian zone is less than the measured temperature, the whole model could be adjusted by increasing the positive action parameters or decreasing the negative action parameters. Thus, the simulations of the hyporheic exchange in the riparian zone are closer to the actual phenomenon.

\section{Conclusions}

With the growing application of heat tracing method in the research of riparian zone problems, a numerical model that could accurate simulate the hydro-thermal dynamics of riparian zones is warranted. In this study, a hydro-thermal coupling mathematical model of the riparian zone based on the thermal conductivity model was constructed. The calibrated Su et al. (2016) thermal conductivity model exhibited a good fitting effect and could better describe the dynamic process of riparian temperature variations. In the previous modeling process, most scholars considered thermal conductivity as a fixed value based on the type of material; such an approach might not have much impact on the research of vertical hyporheic exchanges but could affect the study of the lateral hyporheic exchange. Indeed, the thermal conductivity value varies with the water content; however, the riparian zone includes both the saturated zone and the unsaturated zone, which differs from the riverbed HZ (fully saturated zone). Thus, it is necessary to consider this issue in the study of the riparian zone hyporheic exchange using the heat tracer method. Such a modeling method could provide a reference for scholars interested in this field in the future. Moreover, the constructed hydro-thermal coupling model of the riparian zone contains many parameters and has a large workload in the process of model calibration. In this study, the Morris global sensitivity analysis method was used to assess the sensitivity of the parameters of the hydro-thermal coupling model, which could be used as a reference for scholars applying this model in the model calibration process. It was hoped that these efforts could provide a reference for scholars interested in the riparian zone modeling in the future.

\section{Acknowledgements}

Funding support for this study was supported by the National Natural Science Foundation of China (Grant No. 51679194), and the Planning Project of Science and Technology of Water Resources of Shaanxi (Grant No. 2019slkj-12), and the Natural Science Foundation of Shaanxi Province (Grant No. 2020JM-448), and the Belt and Road Special Foundation of the State Key Laboratory of Hydrology-Water Resources and Hydraulic Engineering (Grant No. 2019490711).

\section{Conflict of Interest}

The authors declare no conflict of interest.

\section{References}

1. HESTER E.T., GOOSEFF M.N. Moving beyond the banks: hyporheic restoration is fundamental to restoring ecological services and functions of streams. Environmental Science \& Technology, 44 (5), 1521, 2010.

2. ZOUNEMAT-KERMANI M., KISI O., ADAMOWSKI J., RAMEZANI-CHARMAHINEH A. Evaluation of data driven models for river suspended sediment concentration modeling. Journal of Hydrology, 535, 457, 2016.

3. PERALTA-MARAVER I., REISS J., ROBERTSON A.L. Interplay of hydrology, community ecology and pollutant 
attenuation in the hyporheic zone. Science of the Total Environment, 610, 267, 2018.

4. LEMKE D., LIAO Z.J., WOHLING T., OSENBRUCK K., CIRPKA O.A. Concurrent conservative and reactive tracer tests in a stream undergoing hyporheic exchange. Water Resources Research, 49 (5), 3024, 2013.

5. LIAO Z.J., LEMKE D., OSENBRUCK K., CIRPKA O.A. Modeling and inverting reactive stream tracers undergoing two-site sorption and decay in the hyporheic zone. Water Resources Research, 49 (6), 3406, 2013.

6. FOX A., BOANO F., ARNON S. Impact of losing and gaining streamflow conditions on hyporheic exchange fluxes induced by dune-shaped bed forms. Water Resources Research, 50 (3), 1895, 2014.

7. FOX A., LAUBE G., SCHMIDT C., FLECKENSTEIN J.H., ARNON S. The effect of losing and gaining flow conditions on hyporheic exchange in heterogeneous streambeds. Water Resources Research, 52 (9), 7460, 2016.

8. HESTER E.T., GOOSEFF M.N. Moving beyond the banks: hyporheic restoration is fundamental to restoring ecological services and functions of streams. Environmental Science \& Technology, 44 (5), 1521, 2010.

9. ROSHAN H., RAU G.C., ANDERSEN M.S., ACWORTH I.R. Use of heat as tracer to quantify vertical streambed flow in a two-dimensional flow field. Water Resources Research, 48, W10508, 2012.

10. SU X.R., SHU L.C., LU C.P. Impact of a low-permeability lens on dune-induced hyporheic exchange. Hydrological Sciences Journal-Journal Des Sciences Hydrologiques, 63 (5), 818, 2018.

11. REN J., WANG X.P., SHEN Z.Z., ZHAO J., YANG J., YE M., ZHOU Y.J., WANG Z.H. Heat tracer test in a riparian zone: Laboratory experiments and numerical modelling. Journal of Hydrology, 563, 560, 2018.

12. REN J., ZHANG W.B., YANG J., SHEN Z.Z., ZHAO J., ZHOU Y.J., WANG Z.H. A comparison of numerical and $\mathrm{Lu}$ modeling of water flow and heat transport with laboratory experiments. Environmental Earth Sciences, 78 (8), 267, 2019.

13. REN J., ZHANG W.B., YANG J., ZHOU Y.J. Using water temperature series and hydraulic heads to quantify hyporheic exchange in the riparian zone. Hydrogeology Journal, 27 (4), 1419, 2019.

14. HIRAIWA Y., KASUBUCHI T. Temperature dependence of thermal conductivity of soil over a wide range of temperature $\left(5-75^{\circ} \mathrm{C}\right)$. European Journal of Soil Science, 51, 211, 2000.

15. SMITS K.M., SAKAKI T., HOWINGTON S.E., PETERS J.F., ILLANGASEKARE T.H. Temperature dependence of thermal properties of sands across a wide range of temperatures $\left(30-70^{\circ} \mathrm{C}\right)$. Vadose Zone Journal, 12 (1), 2013.

16. PALACIOS A., CONG L., NAVARRO M.E., DING Y.L., BARRENECHE C. Thermal conductivity measurement techniques for characterizing thermal energy storage materials-A review. Renewable \& Sustainable Energy Reviews, 108, 32, 2019.

17. ZHAO D.L., QIAN X., GU X.K., JAJJA S.A., YANG R.G. Measurement techniques for thermal conductivity and interfacial thermal conductance of bulk and thin film materials. Journal of Electronic Packaging, 138 (4), 040802, 2016.

18. JOHANSEN O. Thermal conductivity of soils. Ph.D. thesis, University of Trondheim. 1975.
19. CÔTÉ J., KONRAD J.M. A generalized thermal conductivity model for soils and construction materials. Canadian Geotechnical Journal, 42 (2), 443, 2005.

20. LU S., REN T.S., GONG Y.S., HORTON R. An improved model for predicting soil thermal conductivity from water content at room temperature. Soil Science Society of America Journal, 71 (1), 8, 2007.

21. SU L.J., WANG Q.J., WANG S., WANG W.H. Soil thermal conductivity model based on soil physical basic parameters. Transactions of the Chinese Society of Agricultural Engineering, 32 (2), 127, 2016. [In Chinese]

22. COMSOL Multiphysics Reference Manual, version 4.3b. COMSOL, Inc, www.comsol.com. 2013.

23. NARANJO R.C., SMITH D.W. Quantifying seepage using heat as a tracer in selected irrigation canals, Walker River Basin, Nevada, 2012 and 2013. U.S. Geological Survey Scientific Investigations Report, 2016, 2016.

24. RICHARDS L.A. Capillary conduction of liquids through porous mediums. Physics, 1, 318, 1931.

25. VAN GENUCHTEN M.T. A closed-form equation for predicting the hydraulic conductivity of unsaturated soils. Soil Science Society of America Journal, 44, 892, 1980.

26. HEALY R.W., RONAN A.D. Documentation of computer program VS2DH for simulation of energy transport in variably saturated porous media; modification of the US Geological Survey's computer program VS2DT. USGS Water-Resources Investigations Report, 96, 1996.

27. GABIRI G., BURGHOF S., DIEKKRUGER B., LEEMHUIS C., STEINBACH S., NASCHEN K. Modeling spatial soil water dynamics in a tropical floodplain, East Africa. Water, 10 (2), 191, 2018.

28. ZOUNEMAT-KERMANI M., KISI O., ADAMOWSKI J., RAMEZANI-CHARMAHINEH A. Evaluation of data driven models for river suspended sediment concentration modeling. Journal of Hydrology, 535, 457, 2016.

29. ENGELHARDT I., PROMMER H., MOORE C., SCHULZ M., SCHUTH C., TERNES T.A. Suitability of temperature, hydraulic heads, and acesulfame to quantify wastewater-related fluxes in the hyporheic and riparian zone. Water Resources Research, 49 (1), 426, 2013.

30. GERECHT K.E., CARDENAS M.B., GUSWA A.J., SAWYER A.H., NOWINSKI J.D., SWANSON T.E. Dynamics of hyporheic flow and heat transport across a bed-to-bank continuum in a large regulated river. Water Resources Research, 47, W03524, 2011.

31. LU C.P., CHEN S., ZHANG Y., SU X.R., CHEN G.H. Heat tracing to determine spatial patterns of hyporheic exchange across a river transect. Hydrogeology Journal, 25 (6), 1633, 2017.

32. CHEN X.B., CARDENAS M.B., CHEN L. Threedimensional versus two-dimensional bed form-induced hyporheic exchange. Water Resources Research, 51 (4), 2923, 2015

33. HE H.L., ZHAO Y., DYCK M.F., SI B.C., JIN H.J., LV J.L., WANG J.X. A modified normalized model for predicting effective soil thermal conductivity. Acta Geotechnica, 12 (6), 1281, 2017.

34. ANDERSON M.P. Heat as a ground water tracer. Ground Water. 43 (6), 951, 2005.

35. FLORIDES G., KALOGIROU S. Annual ground temperature measurements at various depths. In: 8th REHVA World Congress, Clima, Lausanne. 2005.

36. ENGELHARDT I., PIEPENBRINK M., TRAUTH N., STADLER S., KLUDT C., SCHULZ M., SCHUTH C., TERNES T.A. Comparison of tracer methods to quantify 
hydrodynamic exchange within the hyporheic zone. Journal of Hydrology, 400 (1-2), 255, 2011.

37. LEE J.Y., LIM H.S., YOON H.I., PARK Y. Stream water and groundwater interaction revealed by temperature monitoring in agricultural areas. Water, 5 (4), 1677, 2013.

38. SOBOL I.M. Sensitivity estimates for nonlinear mathematical models. Mathematical Modelling and Computational Experiment, 1 (4), 407, 1993.

39. FENG K.X., LU Z.Z., YANG C.Q. Enhanced Morris method for global sensitivity analysis: good proxy of Sobol' index. Structural and Multidisciplinary Optimization, 59 (2), 373, 2019.

40. NAGANNA S.R., DEKA P.C., CH S., HANSEN W.F. Factors influencing streambed hydraulic conductivity and their implications on stream-aquifer interaction: a conceptual review. Environmental Science and Pollution Research, 24 (32), 24765, 2017.

41. HATCH C.E., FISHER A.T., RUEHL C.R., STEMLER G. Spatial and temporal variations in streambed hydraulic conductivity quantified with time-series thermal methods. Journal of Hydrology, 389 (3-4), 276, 2010.

42. WESTHOLM L.J. Substrates for phosphorus removalpotential benefits for on-site wastewater treatment?. Water Research, 40 (1), 23, 2006.

43. DELFS J.O., PARK C.H., KOLDITZ O. A sensitivity analysis of Hortonian flow. Advances in Water Resources, 32 (9), 1386, 2009. 